\title{
Comparing Visual and Image Analysis Techniques to Quantify Fusarium Basal Rot Severity in Mature Onion Bulbs
}

\author{
Subhankar Mandal (D) and Christopher S. Cramer*
}

check for updates

Citation: Mandal, S.; Cramer, C.S. Comparing Visual and Image Analysis Techniques to Quantify Fusarium Basal Rot Severity in Mature Onion Bulbs. Horticulturae 2021, 7, 156. https://doi.org/10.3390/ horticulturae7060156

Academic Editor: Jianwei Qin

Received: 28 May 2021

Accepted: 17 June 2021

Published: 19 June 2021

Publisher's Note: MDPI stays neutral with regard to jurisdictional claims in published maps and institutional affiliations.

Copyright: (c) 2021 by the authors. Licensee MDPI, Basel, Switzerland. This article is an open access article distributed under the terms and conditions of the Creative Commons Attribution (CC BY) license (https:/ / creativecommons.org/licenses/by/ $4.0 /)$.
Department of Plant and Environmental Sciences, New Mexico State University, N127 Skeen Hall, P.O. Box 30003 , MSC 3Q, Las Cruces, NM 88003-8003, USA; mandals@nmsu.edu

* Correspondence: cscramer@nmsu.edu; Tel.: +1-575-646-2657

\begin{abstract}
Development of resistant cultivars for Fusarium basal rot (FBR), a fungal disease caused by the soil-borne fungus Fusarium oxysporum f.sp. cepae (FOC), is a major breeding goal for onion breeding programs around the world. Currently, the selection of FBR-resistant bulbs is based on a visual interval or category scale, which is an entirely subjective method. This study aimed to develop an objective approach using digital image analysis to quantify symptom development in the basal plate of dormant bulbs. Digital image analyses were performed after artificially inoculating dormant bulbs of eighty-five United States Department of Agriculture (USDA) Allium cepa accessions with a virulent FOC isolate, 'CSC-515'. An analysis with confocal microscopy identified bright blue-green autofluorescence from FOC-infected tissue, effectively differentiating diseased from healthy tissue. Visual scoring of the FBR symptom was aided by stereo fluorescence microscopic images captured using a green fluorescence protein dual filter to quantify accurately FBR severity in the basal plate tissue. An automatic stepwise image segmentation method was developed that was relatively more accurate than a visual estimation. This method exhibited comparable reliability and precision to visual scoring, but it tended to underestimate FOC infection. To our best knowledge, this is the first comprehensive study to investigate the potential use of image analysis as a viable alternative to conventional visual scoring for FBR symptom development. This method could be used for developing resistant cultivars for onion breeding programs in the near future.
\end{abstract}

Keywords: fluorescence imaging; confocal imaging; stereo fluorescence imaging; Fiji imageJ

\section{Introduction}

Fusarium basal rot (FBR) is one of the most devastating diseases impacting onions across the world. FBR, which affects onion production in the tropical and sub-tropical parts of the world, is caused by the soil-borne saprophytic fungus Fusarium oxysporum f.sp. cepae (FOC). The characteristic visible symptoms of FBR can be observed at all plant growth stages of onion that include damping-off of seedlings, chlorosis and necrosis of leaves, and discoloration of the basal plate tissue [1]. Even though all crop growth stages are susceptible to this disease, early detection of this disease is not always possible as a minor infection in the basal plate tissue often goes undetected. As a result, a substantial loss of marketable bulbs occurs because the disease appears to reduce bulb weight and increases bulb rot leading to secondary infections with a favorable environment during storage $[2,3]$.

An effort to establish accurate disease severity estimation in plants was acknowledged in the late 1800s to the early 1900s with cereal crop diseases [4]. Since then, a number of measures have been taken to improve its efficiency, which has led to the development of various visual scales, such as nominal, ordinal, interval, and ratio scales, to assess plant diseases [4]. As FBR causes considerable damage in dormant bulbs during storage, disease estimation in this growth stage is of paramount importance. The scoring of FBR diseaseaffected bulbs is based on an interval or category scale of 1 through 9 , where 1 implies 
no disease and 9 implies $70 \%$ or more diseased basal plate tissue by area [2,5]. Despite the advantage of being quick and requiring easy training of the raters, a visual rating is purely subjective. Several factors, such as the rater's intrinsic ability, value preferences, the physical state of the infected area, plant part being scored, time of the day for scoring, and symptom complexity, were found to be the sources of error and determined the quality of a visual disease estimation [4]. As an example, severity measures of citrus canker on leaves rated by three plant pathologists with a combined experience of more than 70 years revealed an increasing tendency of overestimation, less accuracy and precision with an increase in the actual diseased area [6]. Due to the lack of any alternate method of estimating FBR, a less subjective disease estimation method would benefit FBR resistance breeding programs in onion.

One way to select resistant plant materials objectively is to score the diseased area in a basal plate with an image analysis aid [7]. Digital photographs of the affected plant parts, which are used in image analysis to identify plant diseases and quantify the development of its causal organisms, could be captured via inexpensive devices, such as film cameras, digital cameras, and scanners [4] or by using more expensive systems, such as stereo fluorescence microscopy [8], confocal microscopy [9], and hyperspectral imaging [10]. The digital images generated are subsequently analyzed to quantify disease severity using image analysis software that is either available for free, such as Fiji ImageJ [11] and Scion image (Scion Corp., Fredrick, MD), or for a fee, such as Assess (American Phytopathological Society Press, St Paul, MN, USA).

Even though onion is among the top horticultural commodities globally [12], the biotic stress detection system for this crop is not well established. This lack of development could be attributed to a lack of collective research effort in onion as a result of its biennial, highly cross-pollinated, and day-length-specific nature $[12,13]$. The lack of advancement in onion disease quantification could be easily discernable if compared with disease quantification of the economically important vascular plant diseases. Color imaging, hyperspectral and thermal imaging, visible/near-infrared leaf reflectance, and more advanced, 3D deep learning technologies were used as objective disease quantification methods of vascular wilt of olive (Verticillium dahliae), Fusarium wilt of tomato (Fusarium oxysporum), charcoal rot of soybean (Macrophomina phaseolina), and Fusarium wilt of banana (Fusarium oxysporum f. sp. cubense) [14-17]. Some of these systems are capable of picking up the very sensitive signal wavelengths related to the physiological changes enabling rapid detection of the early symptoms or can utilize these signature wavelengths in models capable of classifying different stages of a disease [14-16]. In onion, a monitoring system, which utilized a highresolution camera system, has been used for detecting the presence of downy mildew in large field trials [18]. However, this system was not intended for diagnosing the disease [18]. For mature bulb postharvest quality, shortwave infrared hyperspectral imaging and optical coherence tomography were used in onion to detect sour skin disease [19] and neck rot disease [20], respectively.

In plant species, only a minimal number of image analysis studies have been investigated for in-ground plant parts, such as roots and tubers [4,21-24]. Being a model plant species, a root tip bioassay has been used in onion for a long time to study the toxic effects of herbicide, fertilizer, insecticides, fungicides, and heavy metals in cellular functions, as known as cytotoxicity and genotoxicity, using light and transmission electron microscopes image analyses [25]. However, no image analysis technique has been conducted to detect FBR in mature onion bulbs to the best of our knowledge. The most apparent reason for the lack of effort was the nature of FOC infection. FOC infection develops internally in the basal plate tissue and could be visible externally only when FOC completely consumes the basal plate tissue and attracts secondary pathogens [3]. Besides nonvisible internal infection, the onion bulb's three-dimensional structure could be a possible source of error for visible scoring as different plant structures and their orientations result in variation affecting the quality of the visual estimation [4]. Even with digital images of a cut onion basal plate, there could be a limitation due to reflective surfaces [4] associated with liquid exudates 
from the exposed tissue. We hypothesized that an effective objective means to estimate FBR disease infection could be generated by capturing fluorescent images of irradiated onion basal plates with the nonvisible wavelength radiation in a fixed orientation of the bulb, and those estimations would be positively correlated in a strong fashion with visual scoring of the same diseased tissue. This study aimed to develop an objective scoring technique for FBR severity on the onion basal plate tissue using digital image analysis techniques and to compare its efficiency with visual scoring.

\section{Materials and Methods}

\subsection{Plant Material}

Eighty-five plant introduction (PI) accessions were selected from the National Plant Germplasm System, USDA, Allium cepa collection for this study depending on the availability of seeds. These accessions have not been screened for FBR resistance/susceptibility previously and produced bulbs of diverse sizes and shapes. From our current germplasm, 'NuMex Crimson' [26] and 'Serrana' (Monsanto Vegetable Seeds, Woodland, CA, USA) were included in this study as checks based on their susceptibility and partial resistance, respectively, in earlier trials at New Mexico State University (NMSU) [2].

\subsection{Field Production of Mature Bulbs}

The field trial was conducted at the Fabian Garcia Science Center (FGSC) of NMSU during the 2018-2019 cropping season. Seeds of the accessions were sowed in the greenhouse before being transplanted into fields with raised beds of $5.5 \times 0.56 \mathrm{~m}^{2}$ in size. The beds were arranged in a randomized complete block design with three replications per accession. The cultural practices followed, such as land preparation, seeding, transplanting, fertigation, weed control, etc., were those as specified for southern New Mexico [27]. Mature bulbs were harvested during the summer of 2019 after $80 \%$ of the plant tops had lodged.

\subsection{Artificial Inoculation of Mature Bulbs}

Inoculum of a virulent FOC isolate, 'CSC 515', was grown on the potato dextrose agar (PDA) medium [28]. This isolate was one of 17 FOC isolates collected from the FGSC at NMSU and tested on eight onion entries for their pathogenicity [28]. 'CSC-515' was recommended for future screening of FBR-resistant germplasm due to its ability to separate FBR susceptible and resistant individuals efficiently [28]. Spore suspensions were then prepared by scrapping the top of growing mycelia from fully grown plates into distilled water [2]. Afterwards, a special PDA medium was prepared by mixing the spore suspension at a concentration of $3.0 \times 10^{4}$ spores $\mathrm{mL}^{-1}$. This medium was prepared the night before inoculation to minimize spore germination and concentration changes. Individual bulbs were inoculated by placing $1 \mathrm{~cm}$ diameter PDA plugs with suspended spores on the top of transversally cut (approximate section thickness $0.25-0.30 \mathrm{~mm}$ ) basal plates. All of the inoculated bulbs of one entry were placed inside a single black plastic crate $\left(58 \times 37 \times 22 \mathrm{~cm}^{3}\right)$ (Bekuplast $\mathrm{GmbH}$, Ringe, Germany) with the inoculated surface facing upwards. These crates were covered with black polyethylene bags $\left(83.8 \times 104 \times 0.00254 \mathrm{~cm}^{3}\right.$, Poly-America, Grand Prairie, TX, USA) for $24 \mathrm{~h}$ to create high humidity conditions and were removed afterwards to facilitate disease development. Proper disease development was ensured by inoculating the susceptible check, and re-inoculation was conducted if the disease incidence was not over $90 \%$ within $12-15$ days. These crates were incubated in the shelves of a wooden shed with proper ventilation in the ambient high summer temperature of New Mexico.

\subsection{Visual Scorings of the Infected Bulbs for FBR Severity}

After $21 \mathrm{~d}$ of incubation, the FBR severity of each inoculated bulb was calculated using two manual scoring methods. The first method utilized visual scoring (VS) of the raw bulbs. For this method, twenty bulbs of each entry were selected arbitrarily from each crate 
(comprising all bulbs from a single replication), cut transversally, and rated for FBR disease severity on a scale of 1 to 9 [2,5]. In this scale, 'one' represented no FBR discoloration in the basal plate, 'two' indicated $1-10 \%$ of the basal plate was showing FBR discoloration, and $10 \%$ increments in disease symptoms for every subsequent increase in the scale [2,5]. Scale 'nine' indicated that most of the basal plate was infected with FBR $(>70 \%$ basal plate area) $[2,5]$.

\subsection{Visual Scorings of the Digital Images for FBR Severity}

The second manual method was visual scoring of digital images (VSDI) captured using stereo fluorescence microscope (Figure 1).

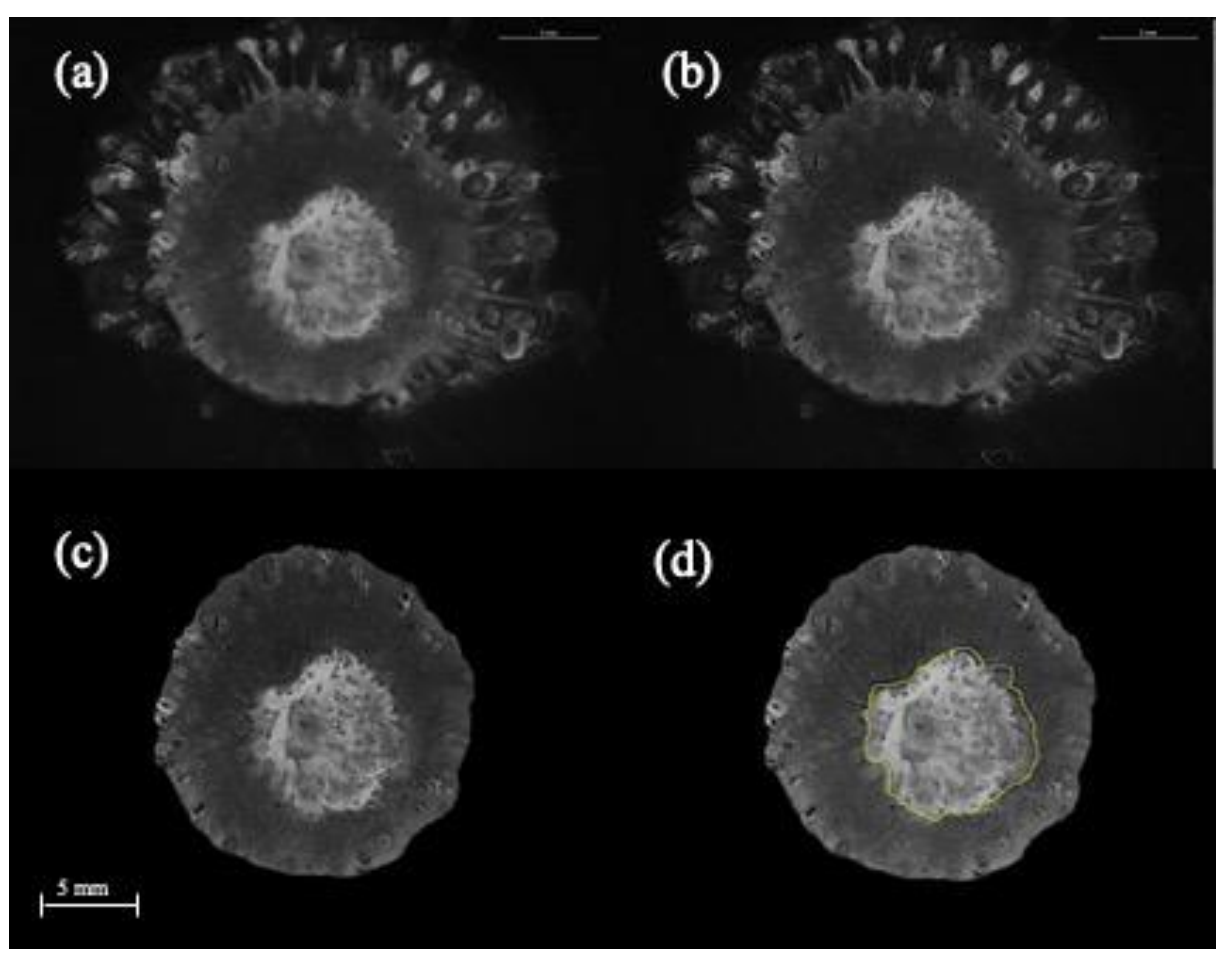

Figure 1. Visual scoring of digital images (VSDI) method of inoculated basal plate image for calculating FBR severity using Fiji Image ${ }^{\odot}$ : (a) raw image of an FOC-infected basal plate, (b) improving the image for better contrast, (c) manual cropping of the total basal plate area of interest, (d) manual demarking of the FOC infection to calculate infected area percentage in pixels or FBR severity. Bar length $=5 \mathrm{~mm}=224$ pixels or 44.8 pixels $/ \mathrm{mm}$, pixel aspect ratio $=1.0$.

For the VSDI scoring, the inoculated mature bulbs were subjected to digital image analysis to develop an objective FBR-severity technique. Confocal images were captured using a Leica TCS SP5 II Confocal Microscope (Leica Microsystems Inc., Buffalo Grove, IL, USA) to identify fluorescence intensities of the healthy and FOC-infected basal plate tissue. FOC-infected basal plate tissue was irradiated using a $405 \mathrm{~nm}$ laser, and the resulting emission was collected between $415 \mathrm{~nm}$ and $700 \mathrm{~nm}$. As a confocal microscope captures images in a very small area, stereo fluorescence images were captured using a Leica ${ }^{\circledR}$ M165FC (Leica Microsystems Inc., Buffalo Grove, IL, USA) to assess the emission spectra from the infected tissue. The stereo fluorescence microscope was equipped with a (metal halide lamp, Model EL6000) mercury lamp and various dual filters, which were used as excitation and barrier filters. We used four different filter sets, green fluorescent protein (GFP) (excitation-425/60 nm (395-455 nm) and barrier-480 LP), Texas red (excitation$560 / 40 \mathrm{~nm}(540-580 \mathrm{~nm})$ and barrier-610 LP), ultraviolet (excitation-360/40 nm (340$380 \mathrm{~nm}$ ) and barrier-420 LP), and violet (excitation-425/40 nm (405-445 nm) and barrier$460 \mathrm{LP}$ ) to capture autofluorescence of the infected tissue. The camera setting of the stereo 
fluorescent microscope was exposure $=1 \mathrm{~s} ;$ gain $=5.4 \times ;$ gamma $=1.0 ;$ zoom $=0.73$. The digital pictures were captured on a grayscale.

The digital images of the FOC-infected basal plates captured using the stereo fluorescent microscope were subsequently analyzed using software package Fiji image ${ }^{\odot}$ [11]. All of the RGB images under analysis were converted into 8-bit tiff images with a fixed dimension $(1392 \times 1040$ pixels). These 8-bit images were then enhanced to improve their contrasts (Figure $1 b$ ). Caution was taken for image resolution to avoid overexposure by normalizing the pixels values across 0 to 255 pixels in the $\mathrm{X}$-axis of an image histogram. After adjusting the scale of a known distance of 44.8 pixels $/ \mathrm{mm}$, the improved images were estimated for total basal plate area (Figure 1c) and FOC-infected areas (Figure 1d) manually in pixels within each basal plate. Percentage severity of FBR was calculated as (infected area/total basal plate area) $\times 100$. The actual disease severity values were then used to rate infected bulbs according to the scales described previously for the visual scoring. Scorings for both the VS and VSDI methods were performed by the first author (S.M.) with multiple years of experience of screening resistant onion bulbs for FBR resistance to be consistent in measuring FBR severity.

\subsection{Automated Segmentation of FBR Severity}

A high-throughput image segmentation method was developed based on the images generated by the stereo fluorescence microscope described above. This method was a stepwise segmentation (SWS) method, comprised of a series of steps, more flexible in analyzing the FOC infection in an image (Figure 2).

The same digital images that were used in the VSDI method were also used for this analysis. After setting up the same scale as the VSDI method, the images were enhanced for contrast by normalizing the histogram as mentioned for the VSDI method (Figure 2c). A 'Gaussian Blur' filter was applied to reduce the noise and smooth out edges (Figure 2d). Subsequently, the images were subjected to an automatic multilevel thresholding method [29] to generate a reproducible result and avoid biases (Figure 2e). The threshold images were transformed into binary images by creating a mask (Figure 2f). If any image had gaps within the infected portions, it was filled by the 'Fill holes' function (Figure 2g), and the infected areas were selected to measure the total infection area (Figure 2h). A custom ImageJ Macro script was written to include all the steps and perform high-throughput segmentation of the FOC infection in the basal plate. This language is easy to learn and use by a person with little or no experience in coding. The percentage severity of FBR was calculated as described above for the VSDI method.

\subsection{Statistical Analysis}

The statistical analysis was performed using $S A S^{\circledR}$ Studio in a web-based environment called SAS ${ }^{\circledR}$ OnDemand for Academics (SAS Institute Inc., Cary, NC, USA). Artificially inoculated basal plates showing a range of FBR severity symptoms scores from 2 to 9 (1\% to $>70 \%$ infected area) were selected for the analysis. The VS, VSDI, and SWS scoring methods were compared for their efficiencies of measuring FBR severity with a total of 204 images of basal plates. Out of the three methods, as the VSDI method used manual demarcation of the actual \% basal plate area of FBR symptoms, it was used as a control or true FBR scores to compare efficiencies of the other two methods. Regression analysis (PROC REG) was conducted to determine the relationship between scores measured by the three estimation methods. The single-factor regression model $(y=a+b x)$ was used for this analysis, where the scores obtained by the VS or SWS method were considered as dependent variable $(x)$, and actual scores based on the VSDI method were considered as the independent variable $(y)$. The intercept $(a)$, slope $(b)$, coefficient of determination $\left(R^{2}\right)$, and coefficient of variation $(\mathrm{CV})$ were calculated to test the goodness of fit. An accurate estimation would ensure when $a=0$, and $b=1 . R^{2}$ value close to 1 indicated more reliability in estimating the actual disease severity by the VSDI method $(y)$ as greater variability was explained by the VS or SWS methods $(x)$. In contrast, smaller $C V$ values were the indictor of greater precision of 
disease estimation. Correlation analysis was also performed to establish the strength of the relationship between the estimated (VS or SWS) and actual (VSDI) disease scores.

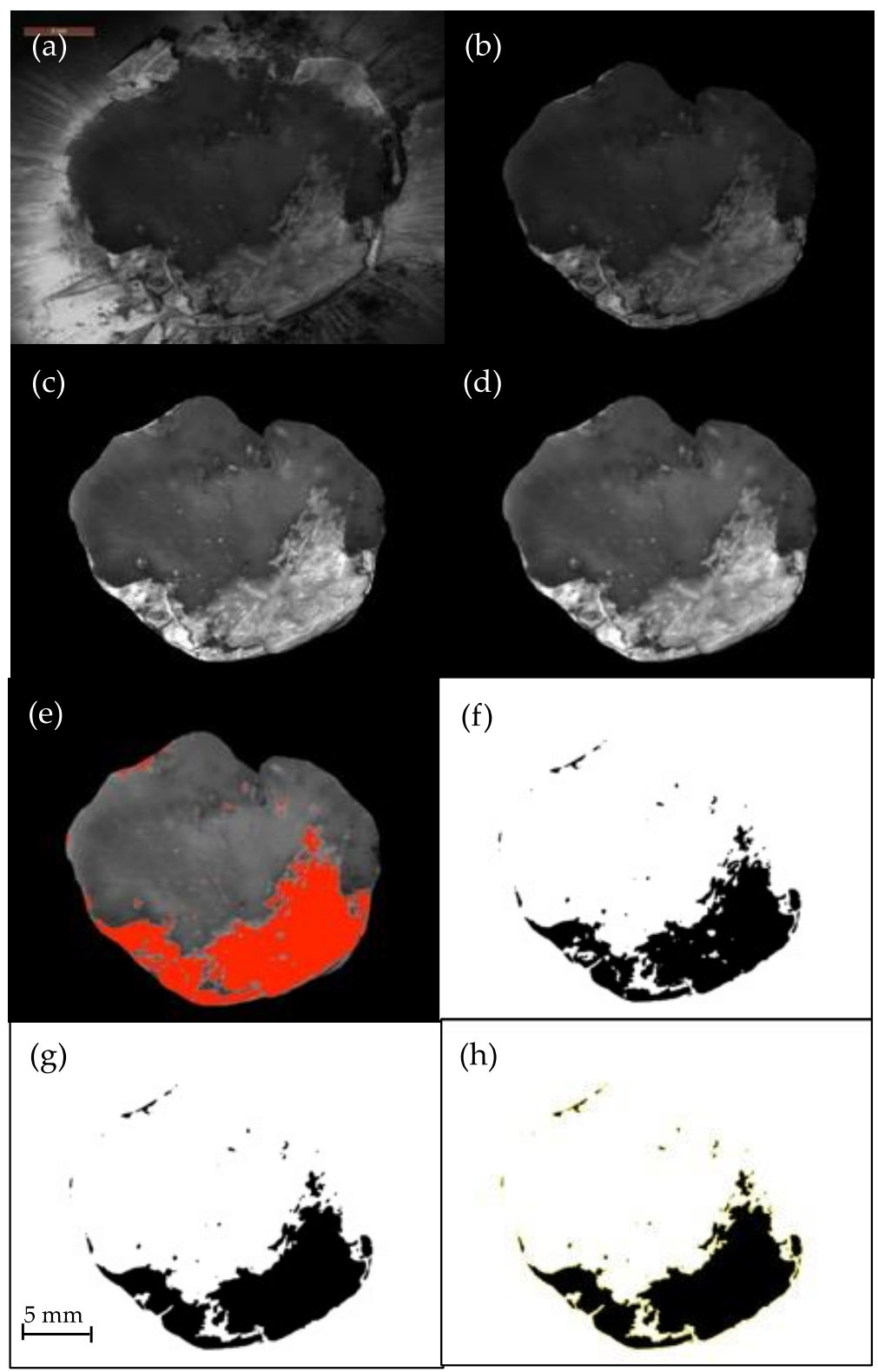

Figure 2. Stepwise segmentation (SWS) method of inoculated basal plate image for calculating FBR severity using Fiji Image ${ }^{\odot}$ : (a) raw image of an FOC-infected basal plate, (b) manual cropping of the total area of interest, (c) improving the image for better contrast, (d) smoothing of the image pixels using 'Gaussian Blur' function, (e) thresholding to select the infected region, (f) masking of the image to transfer it into a binary image, (g) filling holes inside the infected region, (h) demarking of the FOC infection to calculate infected area percentage in pixels or FBR severity. Bar length $=5 \mathrm{~mm}=$ 224 pixels or 44.8 pixels $/ \mathrm{mm}$, pixel aspect ratio $=1.0$.

Even though the above statistical methods visualized the discrepancies between the three methods in measuring FBR severity, they do not measure the repeatability of the measurements, i.e., error and biases in the measurements. Bland-Altman plots [30] were constructed to visualize the bias in a scatter plot. In this plot, the difference between the two methods of disease assessment (bias) is plotted with respect to the mean of the two measurements to decipher any pattern in measurement, i.e., increasing or decreasing bias in the disease scales [31]. 
Differences between the methods $(d)=($ FBR scores of VSDI - FBR scores of VS or SWS)

Mean of the methods $(\mu)=($ FBR scores of VSDI + FBR scores of VS or SWS $) / 2$

95\% confidence interval $=\mu \pm 1.96$ Standard Deviation

Even though the Bland-Altman plot was originally proposed to compare two methods of measurement of systolic blood pressure [30] and was routinely used for clinical trials, it can be used effectively to compare plant disease assessment methods [6].

Due to the three-dimensional shape of onion bulbs, correlation and regression analyses were also performed to investigate whether the bulb size (indicated by basal plate size, $\mathrm{x}$ ) influenced FBR estimation by the three methods (y) of 102 bulbs with various sizes and shapes.

\section{Results}

3.1. Spectral Profile of the Healthy and FOC-Infected Basal Plate Tissue

Bright autofluorescence was observed in the digital images of FOC-inoculated onion basal plate tissue captured via confocal microscopy (Figure 3a).

This autofluorescence generated from the infected basal plate effectively distinguished the diseased tissue from the healthy one. Spectral analysis of two regions of interest selected inside the infected and healthy basal plate tissue further revealed that the emission intensity from the infected region was higher than from the healthy region (Figure 3b). The peak emission intensities of the FOC-infected and healthy regions were observed at $464.8 \mathrm{~nm}$ and $500.5 \mathrm{~nm}$, respectively (Figure $3 \mathrm{~b}$ ). The autofluorescence of the FOC-infected basal plate tissue, which fell in the blue-green region of the white light spectra, helped to identify the right optical filter of the stereo fluorescence microscope for scoring FOC infection with digital images of the basal plates of the PI accessions.

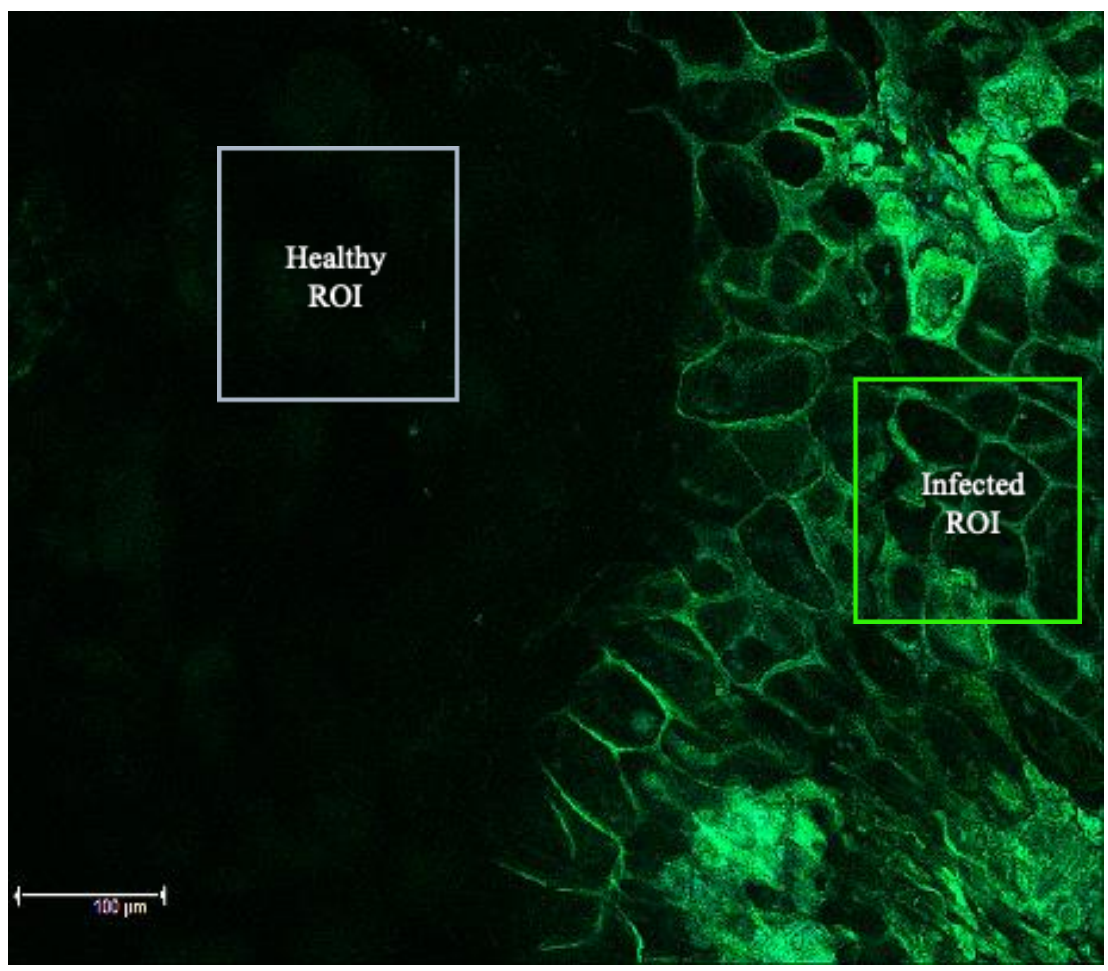

(a)

Figure 3. Cont. 


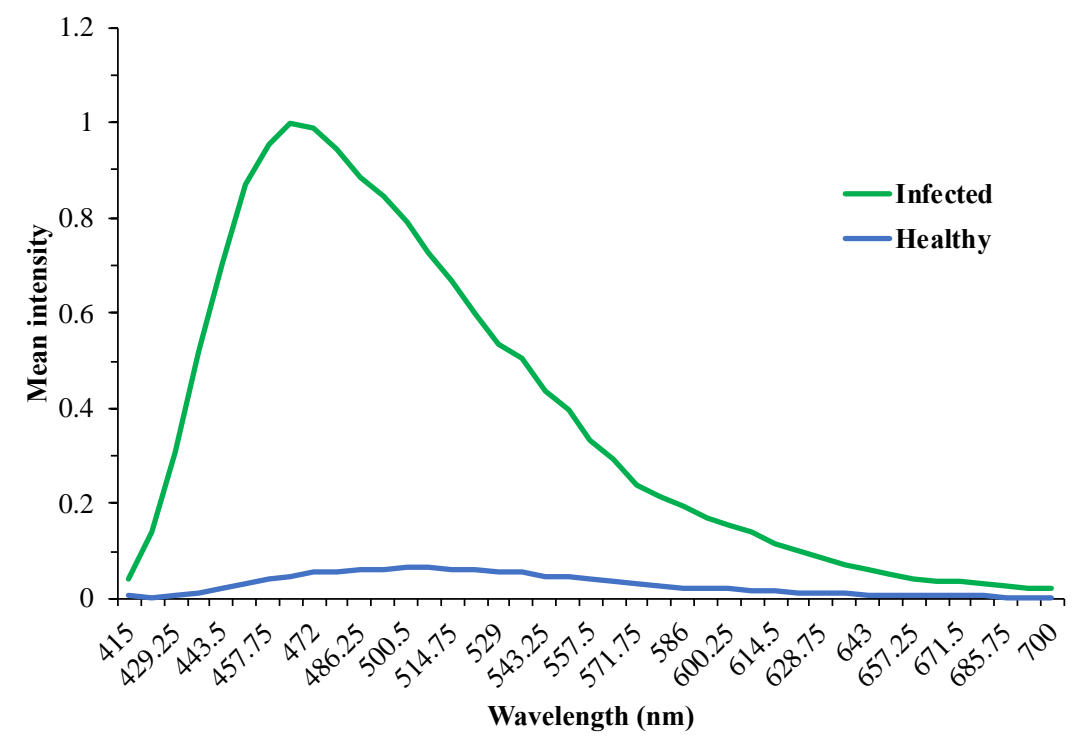

(b)

Figure 3. (a) A digital image of FOC-infected onion basal plate was captured by confocal microscopy. (a) Autofluorescence from the infected and healthy basal plate tissue, (b) a graph showing the difference of the fluorescence emission intensities between two selected regions of interest (ROI) from the infected and healthy basal plate tissue. Bar length $=100 \mu \mathrm{m}$.

\subsection{Comparisons between the Three FBR Severity Estimations}

The visible symptoms of FOC infection were a gray-colored dry rot on the basal plate (Figures 4 and 5).

Among four different filters, the gray-scale images of the inoculated basal plates captured by the GFP dual filter generated the best contrast between the healthy and the infected basal plate areas (Figure 4). With bright autofluorescence from the FOC infection, symptoms were elucidated (Figure 5), and the disease progression on the basal plates was clearer (Figure 5) than was for the visual scoring (Figures 4 and 5).

A stronger positive correlation was obtained between the VSDI and VS $(r=0.73, p$ $<0.0001)$ than between the VSDI and SWS methods $(r=0.58, p<0.0001)$ for estimating the FBR scores. An accurate FBR severity estimation by the VS or SWS methods should generate the intercept $(a)$ and slope $(b)$ values of 0 and 1 , respectively, when compared with the actual FBR severity values obtained by the VSDI method. In this aspect, the SWS method was relatively more accurate ( $a$ and $b$ were 0.88 and 0.93 , respectively) than the VS method ( $a$ and $b$ were 1.40 and 0.60 , respectively), especially with higher magnitudes of severity (Figure 6). For reliability, the $R^{2}$ values should be close to 1 . In this context, both VS or SWS methods had a similar reliability $\left(R^{2}=0.54\right.$ and 0.53 , respectively) of estimating FBR severity in the onion basal plate tissue. As smaller $C V$ values indicate more precise estimation, our result indicated both the SWS $(C V=30.6 \%)$ and VS $(C V=30.2 \%)$ methods could be equally variable in estimating the actual FBR scores.

Another critical observation was for the VS method; there were bulbs with no visible disease scored by naked eye as such but were determined to be infected based on infection fluorescence detected by the VSDI method. For instance, the bulbs, which were scored as 1 (no disease) by the VS method, were scored as 2 and 3 by the VSDI method (Figure 6a). When comparing between VSDI and SWS methods, bulbs scored as infected in one method, were also scored as infected in the other method (Figure 6b). 


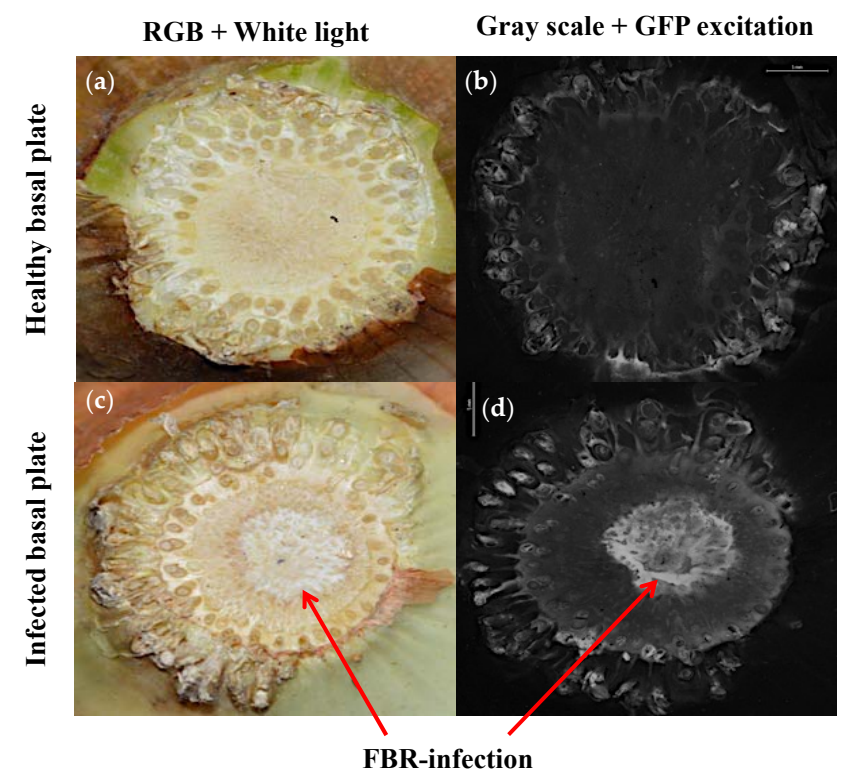

Figure 4. A comparison of digital images of healthy $(\mathbf{a}, \mathbf{b})$ and FOC-infected $(\mathbf{c}, \mathbf{d})$ onion basal plates captured with white light $(\mathbf{a}, \mathbf{c})$ and after GFP excitation $(\mathbf{b}, \mathbf{d})$. FBR symptom was indicated using the red arrows. White light images, captured by a Nikon ${ }^{\odot} 3200$ DSLR camera, give the readers a perspective of visual scoring. Microscopic images were captured using a Leica ${ }^{\circledR}$ M165FC StereoFluorescence microscopy equipped with a Green Fluorescent Protein -1 dual filter (excitation filter$425 / 60 \mathrm{~nm}(395-455 \mathrm{~nm})$; barrier filter $-480 \mathrm{LP})$. Bar length $=5 \mathrm{~mm}=224$ pixels or 44.8 pixels $/ \mathrm{mm}$, pixel aspect ratio $=1.0$.
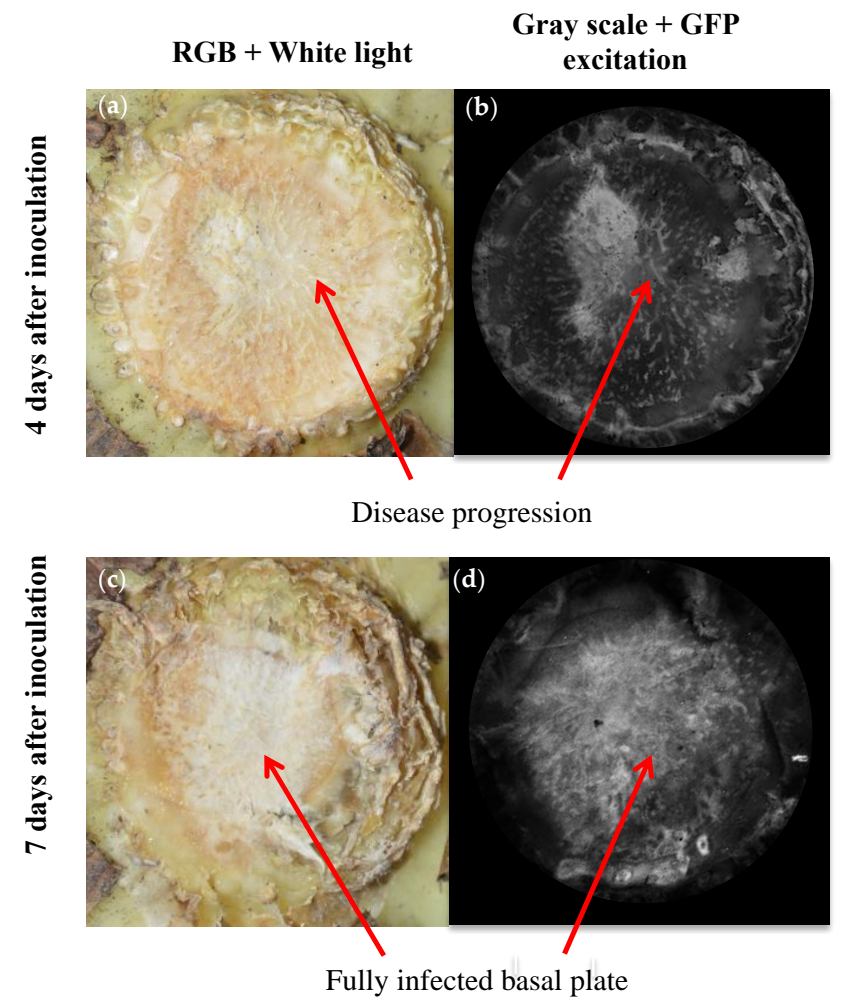

Figure 5. Progression of FOC infection in an onion bulb was better visible with GFP excitation $(\mathbf{b}, \mathbf{d})$ than under white light $(\mathbf{a}, \mathbf{c})$. The basal plate was partially infected four days after inoculation $(\mathbf{a}, \mathbf{b})$ and was infected fully seven days after inoculation $(\mathbf{c}, \mathbf{d})$. The imaging devices and their settings were the same as in Figure 4. 


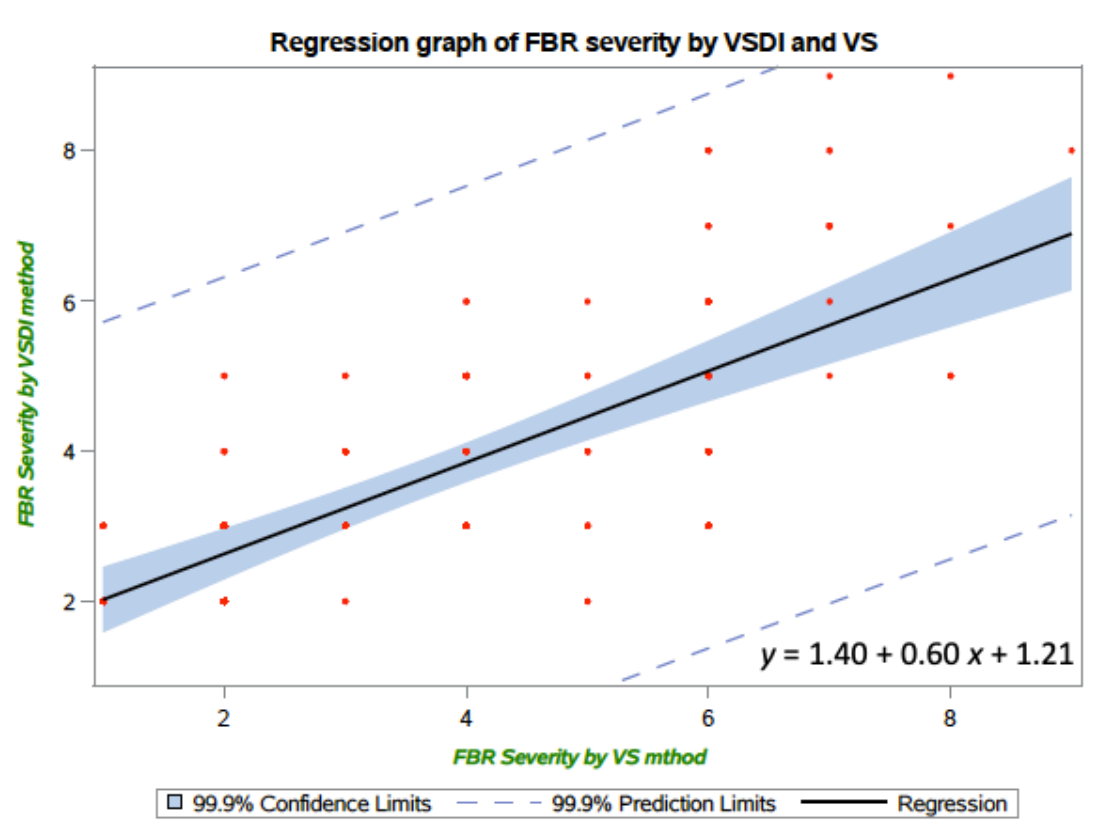

(a)

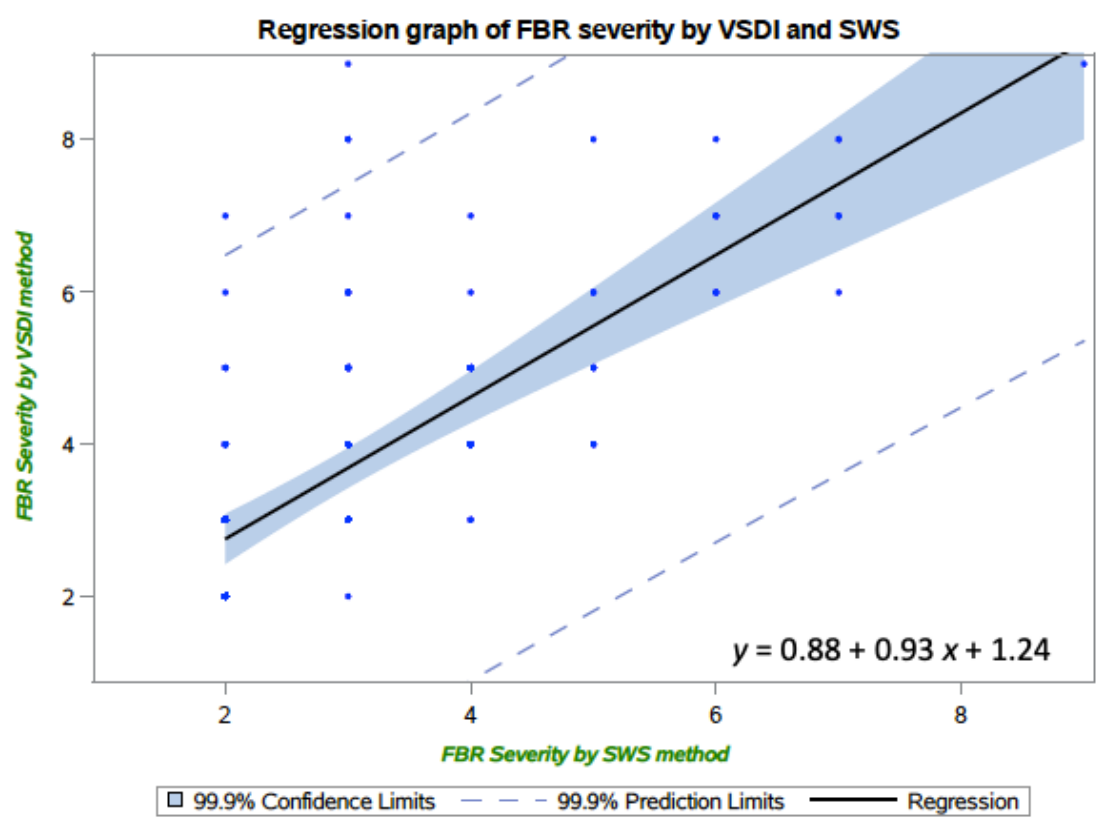

(b)

Figure 6. Regression plots showing the relationship between the three methods to estimate FBR severity in the infected basal plates of mature onion bulbs: (a) between VSDI and VS method and (b) between VSDI and SWS method. Estimated FBR by VSDI method was the dependent variable in each case. $\mathrm{N}=204$.

The Bland-Altman plots further revealed that the mean of the difference between the VSDI and VS methods coincided with the reference line at 0 (Figure 7a). This result indicated that FBR severity measurements obtained by the VS method were not very different than those measurements obtained from the VSDI method, and that there is no bias in estimating actual disease severity by the VS method. 


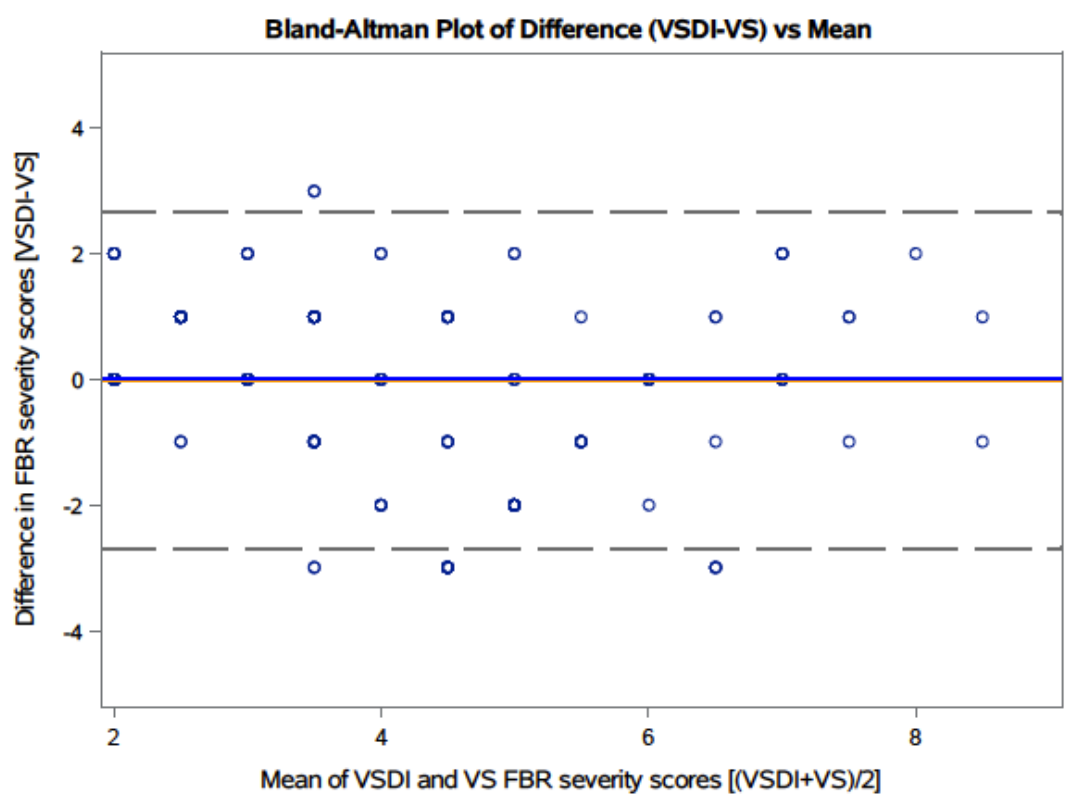

(a)

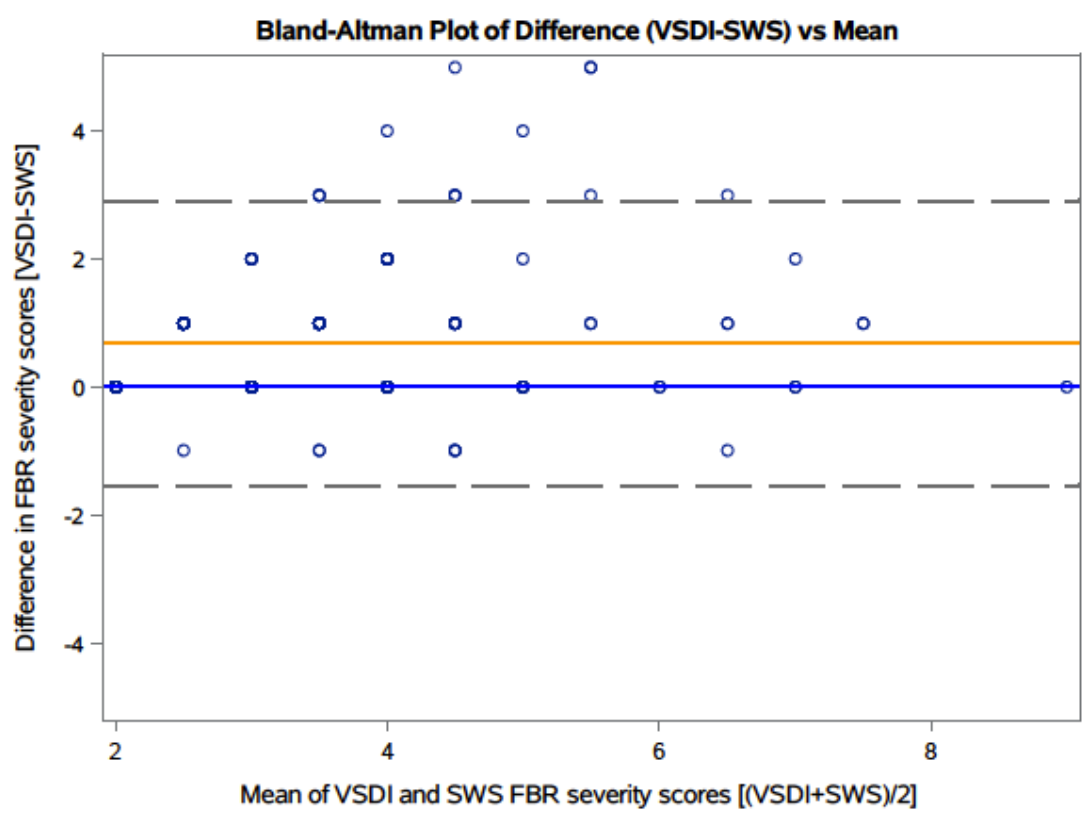

(b)

Figure 7. Bland-Altman plots showing the bias (the difference between two scoring methods) versus the magnitude (mean of two scoring methods) of measuring FBR severity scores in mature onion bulbs: (a) between VSDI and VS method and (b) between VSDI and SWS method. Images of 204 different bulbs were used to generate the data points in the above graphs. The difference was calculated by (severity scores by VSDI method - severity scores by VS or SWS method), and the mean of the two methods was calculated as ((severity scores by VSDI method + severity scores by VS or SWS method) $/ 2$ ). Solid blue line $=$ a reference line at 0 ; solid orange $=$ a reference line at the mean of the difference of the two methods; dashed gray = a reference line at mean \pm 2 standard deviation or $95 \%$ confidence interval.

However, the SWS method underestimated FBR severity values as the mean of the difference between the VSDI and SWS methods were above the reference line at 0 (Figure $7 \mathrm{~b}$ ), i.e., the measurements obtained by the SWS method were lower (positive bias) than the 
VSDI method. A 95\% confidence interval (CI) of the differences, which signified the size of an estimated error, was lower for the SWS method than for the VS method (Figure 7). The upper and lower CI values of the SWS method was between 2.91 and -1.54 (Figure $7 \mathrm{~b}$ ) compared to 2.65 and -2.69 for the VS method (Figure 7a). When the biases (both positive and negative) of individual data points were compared between the two plots, the VS method demonstrated bias in all severity ratings (Figure 7a). A greater degree of bias was demonstrated in the lower disease ratings for the SWS method (Figure 7b).

\subsection{Influence of Bulb Size on FBR Estimation}

No influence of the size of basal plates was observed $\left(R^{2}=0.01\right.$ to 0.02 and $r=-0.15$ to -0.18 ) when estimating severity with any of the three FBR severity estimation methods (Table 1). This indicates that sizes of the bulbs, which determines the total basal plate area, did not influence the biasness observed with the VS or SWS methods of FBR severity estimation.

Table 1. The regression and correlation parameters to determine whether size of the bulb (indicated by basal plate size) influences three methods for estimating FBR severity of onion bulbs.

\begin{tabular}{ccccccc}
\hline \multicolumn{2}{c}{ Correlation } & & \multicolumn{2}{c}{ Regression Parameters $^{\mathbf{1}}$} & \multicolumn{2}{c}{ Parameters $^{2}$} \\
\hline $\boldsymbol{y}$ Variable & $\boldsymbol{x}$ Variables & $\boldsymbol{a}$ & $\boldsymbol{b}$ & $\boldsymbol{R}^{\mathbf{2}}$ & $\boldsymbol{C V}$ & -0.15 \\
\hline VSDI method & Total BP area & $4.0^{* * *}$ & -0.002 & 0.01 & 43.5 & -0.17 \\
\hline VS method & Total BP area & $4.9^{* * *}$ & -0.003 & 0.02 & 54.3 & 42.4 \\
\hline SWS method & Total BP area & $3.6^{* * *}$ & -0.002 & 0.02 & -0.18 \\
\hline
\end{tabular}

${ }^{1}$ A single-factor regression model $(y=a+b x)$ was used for this analysis, where the scores obtained by the VS or SWS method were considered as dependent variables $(x)$, and actual scores based on the VSDI method were considered as the independent variable $(y)$. Regression parameters, intercept $(a)$, slope $(b)$, coefficient of determination $\left(R^{2}\right)$, and the coefficient of variation $(C V)$ were calculated to test the goodness of fit. ${ }^{2}$ Pearson's product-moment correlation coefficient. ${ }^{* * *}$ Significant at $p<0.001$.

\section{Discussion}

4.1. Blue-Green Autofluorescence Resulted in a Sharp Contrast between Healthy and FOC-Infected Basal Plate Tissue

The peak fluorescence emission intensities of $464.8 \mathrm{~nm}$ and $500.5 \mathrm{~nm}$ (Figure 3), which were detected from the FOC-infected and healthy regions, respectively, both fall in the blue $(464-500 \mathrm{~nm})$ and blue-green region $(<520-530 \mathrm{~nm})$ of white light. It is difficult to conclude whether this fluorescence is coming from the fungus or the degraded cell walls. A study involving confocal microscopy of Fusarium graminearum-inoculated maize stem tissue with a $405 \mathrm{~nm}$ excitation - captured a hyphal fluorescence emission of $460-500 \mathrm{~nm}$ and a cell wall fluorescence of 570-670 nm [32]. In reference to this study, the healthy onion basal plate tissue emitted both fungal and cell wall fluorescence, and the infected basal plate tissue likely generated an emission in the hyphal fluorescence range (Figure 3b). Comparing both the healthy and infected basal plate tissue generated autofluorescence, fluorescence emission intensity from the healthy tissue was weaker (Figure 3). This difference in emission intensity has been useful for determining the severity of fungal infection at the cellular level. For example, collapsing and non-collapsing mesophyll cells of barley leaves inoculated with Erysiphe graminis f.sp. hordei could be distinguished based on the weaker fluorescence from the non-collapsing mesophyll cells [33]. This finding aligned with our observation of low-intensity fluorescence emission from the apparent healthy basal plate tissue (Figure 3).

Comparing the emission spectra between FOC-infected and healthy onion basal plate tissue also showed the limitations of visual estimation of an actual diseased area. Visual estimation and confocal image analysis were performed on the same bulbs twenty days after inoculation when FBR encompassed most of the basal plate area in a susceptible bulb [2]. Even though the visual estimation identified a healthy region in the basal plate tissue, confocal image analysis of the tissue showed a peak intensity of $500.5 \mathrm{~nm}$, an 
emission close to hyphal fluorescence (Figure 3) [32]. This emission suggested that apparent healthy tissue may harbor pathogenic fungal growth, which fluoresces in the blue-green region [34]. Blue-green fluorescence could originate from secondary metabolites, such as phenolics, in the host cells surrounding the infected ones as a defense-related response [35]. Hypersensitive reactions of plant cells can generate autofluorescence from the papilla, halo, and lateral wall of the epidermal cells [33]. Phenolics, such as feruloyl-3'-methoxytyramine and feruloyltyramine, which were found in the granular deposits of onion epidermal cell walls as a defense reaction materials against Botrytis allii penetration, produce blue fluorescence under UV irradiation [36]. Alongside host cell wall degradation, intense fluorescence could also be a product of fungal phenolics and cytoplasmic materials, and it indicates fungal viability $[37,38]$. We assumed that the diseased basal plate tissue could be in its last stage of infection, when no apoplast sugar was available to sustain the fungal growth [3]. Confirmation of the origin of the autofluorescence is needed from a detailed histological study involving FOC-infected basal plate tissue from both susceptible and resistant onion bulbs, which was beyond the scope of this study.

\subsection{Image Analyses Proved to Be a Suitable Alternative to Visual Estimation for FBR Quantification of Onion Bulbs}

Despite a single discolored lesion produced by FOC in the basal plate (Figure 4), the lowest accuracy was obtained with the VS method. The main reason was the lack of color contrast of FBR symptoms in the inner basal plate tissue (Figure S1), unlike the conspicuous symptoms of yellowing, necrotic, and chlorotic lesions in leaves [3]. The inconspicuous gray discoloration caused by FBR on healthy white tissue of the basal plate was not very apparent to the naked eye (Figures 4 and 5), especially when the symptomatic area was very small. This subjective nature of the visual quantification was apparent as the VS method could not detect some bulbs with $<20 \%$ infection (scored 2 and 3), which were detected by the VSDI method (Figure 6a). Studies showed that lesion size had a significant influence on the accuracy and precision of the visual disease estimation [4,21]. Larger and coalesced lesions were estimated more precisely than smaller and dispersed lesions, which were generally overestimated [21,39-41]. This could explain the lack of bias in the VS method compared to the actual diseased area obtained by the VSDI method (Figure 7a) as the FBR symptoms in the basal plate tissue are mostly a single discolored lesion (Figure 4).

The manual estimation of the VS method, when aided with digital images comprising actual diseased area with autofluorescence in the VSDI method, produced the best result in this study. Apart from the single lesion, autofluorescence of the FOC-infected basal plate tissue in the grayscale images created monochromatic pictures for a discernible and more accurate estimation of the diseased area. The accuracy came from some underlying advantages of this technique. As the infection was readily detected by autofluorescence, this method eliminated the likelihood of over or under-estimation, which is due to rater bias related to the VS method [42]. The grayscale imaging reduced the possibility of an error in disease estimation by eliminating a reflective surface or overexposure, which was generally related to the light source [4]. Smaller and most of the hard-to-find infections by the rater could also be detected using this method. As the fluorescence intensity changed with the severity of the infection, this method could decipher FBR resistance resulting from hypersensitive reactions [33] and fungal viability $[37,38]$ in order to select resistant bulbs. Fluorescent imaging could detect the presence of infection earlier than 12-14 days required for visible symptoms to appear in stored bulbs [43].

Even with the VSDI method's advantages over the VS method in terms of less subjectivity and more accuracy, it was a slow method that required a manual disease area estimation. In this regard, the SWS method had the advantage of reducing the estimation time significantly. In this study, the SWS method exhibited comparable reliability and similar variability with the VS method across the disease severity ranges but was more accurate in estimating FBR severity scores (Figure 6). Although severity estimation of the SWS method improved with higher FBR ratings (Figure $7 \mathrm{~b}$ ), this method underestimated the severity at lower ratings, which could be a consequence of the image segmentation 
procedure. As auto thresholding was solely based on the bright pixel intensity of the infected area, it might not include pixels with a lower inflorescence intensity that might result from a lower infection severity or the initial stages of infection. Limitations of digital image analysis for plant diseases quantification are mainly due to the lack of discrimination between diseased and healthy tissue by the image capturing system [44,45]. Conventional histochemical stains and autofluorescence could improve the discrimination between healthy and infected tissue when low amounts of pathogen are present [34]. The present process does not require lengthy disease estimation training or coding expertise, which is an essential consideration for a plant breeding program that involves limited number of, and frequently changing, research personnel.

\subsection{The Future Challenges and the Prospects of Digital Image Analysis in Onion Breeding}

The imaging system for onion bulbs was destructive in nature $[19,20]$ and required nondestructive approaches for quality control in the packaging line. Spectral differences obtained between the FOC-infected and healthy basal plates in this study indicated the possible use of hyperspectral imaging as a nondestructive FBR screening strategy [19]. The accuracy of detecting healthy and Fusarium head blight-infected plant parts from hyperspectral imaging systems was reported to be as high as $78-89 \%$ when used alone or in combination with other sensory detection methods [10]. A typical FBR symptom in mature onion bulbs was detected 12-14 days after inoculation when using a disease conducive environment [43]. Early detection of fungal infection by optical sensors capable of detecting fluorescence from undisturbed basal plates could reduce shipment losses related to FBR that develops during storage [46].

In this study, we used FOC infection caused by a single Fusarium species, FOC, to develop the image analysis protocol as FOC is known to be the primary causal agent of FBR in the southern New Mexico region and other parts of the world [28,43,47,48]. Even though FOC is the most aggressive in developing symptoms during long storage [43,47,48], the demography and virulence of Fusarium spp. might change with the changing climatic variables in the near future [49]. Recent studies revealed the isolation of other Fusarium species, such as F. proliferatum (Matsush.) Nirenberg ex Gerlach and Nirenberg, F. solani (Martius) Saccardo, F. acutatum Nirenberg and O'Donnell, and F. anthofilium (Braun) Wollenw, from FOC-infected onion bulbs $[43,48]$. All these species can produce similar disease symptoms in the mature bulb as FOC [43], which complicates disease estimation as greater accuracy of identifying a plant disease could be accomplished by estimating a single discolored lesion [23] than identifying multiple diseases in the same plant part [24]. The efficiency of image analysis could be improved further by employing simple machine learning algorithms, such as Trainable Weka Segmentation [50] or more complex Deep Neural Networks [23], both of which use the training of image classifiers to decipher complex disease symptoms. Objective quantification of FBR severity using digital image analysis in the present study was an important first step towards achieving a long-term breeding goal of automated screening of FOC-infected mature onion bulbs using machine learning.

\section{Conclusions}

Objective quantification methods were developed to study FBR disease symptoms in mature onion bulbs. Confocal microscopic analysis revealed digital images of the basal plates, captured bright autofluorescence emission in the blue-green region of the visible light generated from the FOC-infected area, and effectively distinguished infected tissue from healthy tissue. A subsequent comparison between a visual and two image analysis methods showed visual estimation with the aid of digital images was the best method to quantify FOC infection of the basal plate objectively. Even though the automatic stepwise image segmentation procedure was more accurate than only visual estimation, it underestimated FOC infection. A more improved image analysis protocol, such as using machine learning algorithms, could be a viable alternative to visual scoring and could 
effectively reduce the time of screening FBR-resistant bulbs to increase the efficiency of onion disease resistance breeding.

Supplementary Materials: The following are available online at https:/ /www.mdpi.com/article/10 .3390/horticulturae7060156/s1, Figure S1: Stereo-fluorescence images of FBR-infected basal plate tissue to show the original color of an FBR infected basal plate after UV excitation without any filter (left).

Author Contributions: Conceptualization, investigation, methodology, data curation, formal analysis, visualization, writing_original draft preparation, writing—review and editing, S.M.; conceptualization, funding acquisition, investigation, supervision, writing - review and editing, C.S.C. Both authors have read and agreed to the published version of the manuscript.

Funding: The authors would like to thank the USDA Root and Bulb Vegetable Crop Germplasm Committee (CGC) for providing financial support in the form of a 2018 Root and Bulb Vegetable CGC award for this study.

Institutional Review Board Statement: Not applicable.

Informed Consent Statement: Not applicable.

Data Availability Statement: The data presented in this study are available upon request from the corresponding author. The data are not publicly available due to privacy concerns.

Acknowledgments: The authors would like to thank Peter Cooke for his valuable review on the first draft of the manuscript. The authors would also like to thank Ray Muhyi and the undergraduate students for their assistance in managing plants in the greenhouse and the field.

Conflicts of Interest: The authors declare no conflict of interest.

\section{References}

1. Cramer, C.S.; Mandal, S.; Sharma, S.; Nourbakhsh, S.S.; Goldman, I.; Guzman, I. Recent advances in onion genetic improvement. Agronomy 2021, 11, 482. [CrossRef]

2. Mandal, S.; Cramer, C.S. An artificial inoculation method to select mature onion bulbs resistant to Fusarium basal rot. HortScience 2020, 55, 1840-1847. [CrossRef]

3. Cramer, C.S. Breeding and genetics of Fusarium basal rot resistance in onion. Euphytica 2000, 115, 159-166. [CrossRef]

4. Bock, C.H.; Poole, G.H.; Parker, P.E.; Gottwald, T.R. Plant disease severity estimated visually, by digital photography and image analysis, and by hyperspectral imaging. CRC Crit. Rev. Plant Sci. 2010, 92, 927-939. [CrossRef]

5. Gutierrez, J.A.; Cramer, C.S. Screening short-day onion cultivars for resistance to Fusarium basal rot. HortScience 2005, 40, 157-160. [CrossRef]

6. Bock, C.H.; Parker, P.E.; Cook, A.Z.; Gottwald, T.R. Characteristics of the perception of different severity measures of citrus canker and the relationships between the various symptom types. Plant Dis. 2008, 92, 927-939. [CrossRef] [PubMed]

7. Barbedo, J.G.A. Digital image processing techniques for detecting, quantifying and classifying plant diseases. Springerplus 2013, 2, 660. [CrossRef] [PubMed]

8. Sarrocco, S.; Falaschi, N.; Vergara, M.; Nicoletti, F.; Vannacci, G. Use of Fusarium oxysporum F. sp. dianthi transformed with marker genes to follow colonization of carnation roots. J. Plant Pathol. 2007, 89, 47-54. Available online: https://www.jstor.org/stable/41 998356 (accessed on 13 June 2021).

9. Jones, K.; Kim, D.W.; Park, J.S.; Khang, C.H. Live-cell fluorescence imaging to investigate the dynamics of plant cell death during infection by the rice blast fungus Magnaporthe oryzae. BMC Plant Biol. 2016, 16, 1-8. [CrossRef]

10. Mahlein, A.K.; Alisaac, E.; Al Masri, A.; Behmann, J.; Dehne, H.W.; Oerke, E.C. Comparison and combination of thermal, fluorescence, and hyperspectral imaging for monitoring Fusarium head blight of wheat on spikelet scale. Sensors 2019, $19,2281$. [CrossRef]

11. Schindelin, J.; Arganda-Carreras, I.; Frise, E.; Kaynig, V.; Longair, M.; Pietzsch, T.; Preibisch, S.; Rueden, C.; Saalfeld, S.; Schmid, B.; et al. Fiji: An open-source platform for biological-image analysis. Nat. Methods 2012, 9, 676-682. [CrossRef]

12. Taylor, A.; Teakle, G.R.; Walley, P.G.; Finch-Savage, W.E.; Jackson, A.C.; Jones, J.E.; Hand, P.; Thomas, B.; Havey, M.J.; Pink, D.A.; et al. Assembly and characterisation of a unique onion diversity set identifies resistance to Fusarium basal rot and improved seedling vigour. Theor. Appl. Genet. 2019, 132, 3245-3264. [CrossRef]

13. Jones, H.A.; Mann, L.K. Onion and Their Allies; Leonard Hill (Books) Limited: London, UK, 1963.

14. Calderón, R.; Navas-Cortés, J.A.; Lucena, C.; Zarco-Tejada, P.J. High-resolution airborne hyperspectral and thermal imagery for early detection of Verticillium wilt of olive using fluorescence, temperature and narrow-band spectral indices. Remote Sens. Environ. 2013, 139, 231-245. [CrossRef] 
15. Marín-Ortiz, J.C.; Gutierrez-Toro, N.; Botero-Fernández, V.; Hoyos-Carvajala, L.M. No Linking physiological parameters with visible/near-infrared leaf reflectance in the incubation period of vascular wilt disease. Saudi J. Biol. Sci. 2020, 27, 88-99. [CrossRef]

16. Nagasubramanian, K.; Jones, S.; Singh, A.K.; Sarkar, S.; Singh, A.; Ganapathysubramanian, B. Plant disease identification using explainable 3D deep learning on hyperspectral images. Plant Methods 2019, 15, 98. [CrossRef] [PubMed]

17. Orr, R.; Pattison, A.; East, D.; Warman, N.; O’Neill, W.; Czislowski, E.; Nelson, P.N. Image-based quantification of Fusarium wilt severity in banana. Australas Plant Dis. Notes 2019, 14, 14. [CrossRef]

18. Kim, W.S.; Lee, D.H.; Kim, Y.J. Machine vision-based automatic disease symptom detection of onion downy mildew. Comput. Electron. Agric. 2020, 168, 105099. [CrossRef]

19. Wang, W.; Li, C.; Tollner, E.W.; Gitaitis, R.D.; Rains, G.C. Shortwave infrared hyperspectral imaging for detecting sour skin (Burkholderia cepacia)-infected onions. J. Food Eng. 2012, 109, 38-48. [CrossRef]

20. Ford, H.D.; Tatam, R.P.; Landahl, S.; Terry, L.A. Investigation of disease in stored onions using optical coherence tomography. Acta Hortic. 2012, 945, 247-254. [CrossRef]

21. Forbes, G.A.; Jeger, M.J. Factors affecting the estimation of disease intensity in simulated plant structures. J. Plant Dis Prot. 1987, 94, 113-120. Available online: https:/ / www.jstor.org/stable/43383217 (accessed on 13 June 2021).

22. Pujari, J.D.; Yakkundimath, R.; Byadgi, A.S. Image processing based detection of fungal diseases in plants. Procedia Comput. Sci. 2015, 46, 1802-1808. [CrossRef]

23. Mohanty, S.P.; Hughes, D.P.; Salathé, M. Using deep learning for image-based plant disease detection. Front. Plant Sci. 2016, 7, 1419. [CrossRef]

24. Oppenheim, D.; Shani, G.; Erlich, O.; Tsror, L. Using deep learning for image-based potato tuber disease detection. Phytopathology 2019, 109, 1083-1087. [CrossRef] [PubMed]

25. Bonciu, E.; Firbas, P.; Fontanetti, C.S.; Wusheng, J.; Karaismailoğlu, M.C.; Liu, D.; Menicucci, F.; Pesnya, D.S.; Popescu, A.; Romanovsky, A.V.; et al. An evaluation for the standardization of the Allium cepa test as cytotoxicity and genotoxicity assay. Caryologia 2018, 71, 191-209. [CrossRef]

26. Cramer, C.S.; Corgan, J.N. “NuMex Crimson” onion. HortScience 2003, 38, 306-307. [CrossRef]

27. Walker, S.; Ashigh, J.; Cramer, C.; Sammis, T.; Lewis, B. Bulb Onion Culture and Management for Southern New Mexico. Coop Exten Serv Circ 563, College of Agr., Consumer and Environment Sciences, NMSU. 2009. Available online: https: / / aces.nmsu.edu/pubs/_circulars/CR563/welcome.html (accessed on 13 June 2021).

28. Saxena, A.; Cramer, C.S. Screening of onion seedlings for resistance against New Mexico isolates of Fusarium oxysporum f. sp. cepae. J. Plant Pathol. 2009, 91, 197-200. Available online: https:/ /www.jstor.org/stable/41998593 (accessed on 13 June 2021).

29. Yen, J.C.; Chang, F.J.; Chang, S. A new criterion for automatic multilevel thresholding. IEEE Trans. Image Process. 1995, 4, 370-378. [CrossRef]

30. Altman, D.G.; Bland, J.M. Measurement in medicine: The analysis of method comparison studies. J. R. Stat. Soc. Ser. D 1983, 32, 307-317. [CrossRef]

31. Giavarina, D. Understanding bland altman analysis. Biochem. Med. 2015, 25, 141-151. [CrossRef] [PubMed]

32. He, J.; Yuan, T.; Tang, W.-H. Fusarium graminearum maize stalk infection assay and associated microscopic observation protocol. Bio Protocol. 2016, 6, e2034. [CrossRef]

33. Mayama, S.; Shishiyama, J. Histological observation of cellular responses of barley leaves to powdery mildew infection by UV-fluorescence microscopy. Jpn. J. Phytopathol. 1976, 42, 591-596. [CrossRef]

34. Roshchina, V.V. Vital autofluorescence: Application to the study of plant living cells. Int. J. Spectrosc. 2012, 124672. [CrossRef]

35. Buschmann, C.; Lichtenthaler, H.K. Principles and characteristics of multi-colour fluorescence imaging of plants. J. Plant Physiol. 1998, 152, 297-314. [CrossRef]

36. McLusky, S.R.; Bennett, M.H.; Beale, M.H.; Lewis, M.J.; Gaskin, P.; Mansfield, J.W. Cell wall alterations and localized accumulation of feruloyl-3'-methoxytyramine in onion epidermis at sites of attempted penetration by Botrytis allii are associated with actin polarisation, peroxidase activity and suppression of flavonoid biosynthesis. Plant J. 1999, 17, 523-534. [CrossRef]

37. Wu, C.H.; Warren, H.L. Natural autofluorescence in fungi, and its correlation with viability. Mycologia 1984, 76, 1049-1058. [CrossRef]

38. Wu, C.H.; Warren, H.L. Induced autofluorescence in fungi and its correlation with viability: Potential application of fluorescence microscopy. Phytopathology 1984, 74, 1353-1358. [CrossRef]

39. Sherwood, R.T. Illusions in visual assessment of stagonospora leaf spot of orchardgrass. Phytopathology 1983, $73,173-177$. [CrossRef]

40. Godoy, C.V.; Carneiro, S.M.T.P.G.; Iamauti, M.T.; Pria, D.M.; Amorim, L.; Berger, R.D.; Filho, A.B. Diagrammatic scales for bean diseases: Development and validation. J. Plant Dis. Prot. 1997, 104, 336-345. Available online: https://www.jstor.org/stable/4321 5167 (accessed on 13 June 2021).

41. Costa, A.P.; Peixoto, J.R.; Blum, L.E.B.; Vilela, M.S.; Nogueira, I.; Castro, A.P.G. Standard area diagram set for quantification of septoriosis in fruit of sour passion fruit. Rev. Bras. Ciências Agrárias Braz. J. Agric. Sci. 2019, 14, e5637. [CrossRef]

42. Chiang, K.S.; Bock, C.H.; Lee, I.H.; El Jarroudi, M.; Delfosse, P. Plant disease severity assessment-how rater bias, assessment method, and experimental design affect hypothesis testing and resource use efficiency. Phytopathology 2016, 106, 1451-1464. [CrossRef] 
43. Kalman, B.; Abraham, D.; Graph, S.; Perl-Treves, R.; Harel, Y.M.; Degani, O. Isolation and identification of Fusarium spp., the causal agents of onion (Allium cepa) basal rot in northeastern Israel. Biology 2020, 9, 69. [CrossRef]

44. Olmstead, J.W.; Lang, G.A.; Grove, G.G. Assessment of severity of powdery mildew infection of sweet cherry leaves by digital image analysis. HortScience 2001, 36, 107-111. [CrossRef]

45. Chungu, C.; Mather, D.E.; Reid, L.M.; Hamilton, R.I. Assessment of ear rot symptom development in maize hybrids inoculated with Fusarium graminearum. Can. J. Plant Pathol. 1997, 19, 390-396. [CrossRef]

46. Pieczywek, P.M.; Cybulska, J.; Szymańska-Chargot, M.; Siedliska, A.; Zdunek, A.; Nosalewicz, A.; Baranowski, P.; Kurenda, A. Early detection of fungal infection of stored apple fruit with optical sensors-Comparison of biospeckle, hyperspectral imaging and chlorophyll fluorescence. Food Control 2018, 85, 327-338. [CrossRef]

47. Galván, G.A.; Koning-Boucoiran, C.F.S.; Koopman, W.J.M.; Burger-Meijer, K.; González, P.H.; Waalwijk, C.; Kik, C.; Scholten, O.E. Genetic variation among Fusarium isolates from onion, and resistance to Fusarium basal rot in related Allium species. Eur. J. Plant Pathol. 2008, 121, 499-512. [CrossRef]

48. Mahdy, H. Identification of Fusarium species causing onion basal rot in Egypt and their virulence on seeds, seedlings and onion bulbs. Ann. Agric. Sci. Moshtohor. 2018, 56, 79-88. [CrossRef]

49. Vaughan, M.; Backhouse, D.; Del Ponte, E.M. Climate change impacts on the ecology of Fusarium graminearum species complex and susceptibility of wheat to Fusarium head blight: A review. World Mycotoxin J. 2016, 9, 685-700. [CrossRef]

50. Arganda-Carreras, I.; Kaynig, V.; Rueden, C.; Eliceiri, K.W.; Schindelin, J.; Cardona, A.; Sebastian Seung, H. Trainable Weka Segmentation: A machine learning tool for microscopy pixel classification. Bioinformatics 2017, 33, 2424-2426. [CrossRef] 